\title{
Religious Affiliations and Social Coexistence in the Islamic Middle East Countries
}

\author{
Giancarlo Rovati
}

$1 \quad$ Introduction

In the contest of our multi-dimensional research on (forced) migrations because of religious reasons, it is particularly interesting to analyze the religious and cultural orientations that characterize Islamic Middle East countries, where several religious minorities are facing heavy difficulties to be accepted and welcomed.

With the aim of focusing on the question of religious tolerance in Islamic countries and understanding how tolerance could be increased, it is particularly useful to consider the information provided by the most recent Arab Barometer surveys, which, since 2006, have been studying Arab people's values, attitudes and behaviors. Among these aspects, careful and close attention is devoted to the relation among religion, civil law, political authorities, and democracy, in addition to the classic religion topics - i.e. beliefs, practices, and sense of belonging.

In this chapter, we will analyze some data collected over the past decade through the third and fourth Arab Barometer survey (carried out in the twoyear period 2012-2014 and in the year 2016-17) based on representative samples of the adult population. They involved, respectively, 12 and 7 Arab countries (Table 7.1) (Arab Barometer, 2012-2014 2016-17) but our analysis will focus only on some of them (Egypt, Jordan, Iraq, Lebanon, Palestine), as they can be compared to each other more directly, from a cultural and geo-political point of view. Unfortunately, Iraq was not included in the 2016 wave, so it is impossible to apply an identical longitudinal comparison to this country.

People living in these five countries have been active subjects and -at the same time- victims of the large and lasting conflicts that have broken out the Middle-East in the last few decades. In the case of Egypt and Iraq, citizens took part in a hopeful democratic experiment -optimistically named Arab Springs (Ghanem, 2018)- based on a pluralistic electoral competition to choose their ruling classes. Despite every optimistic expectation, this democratic process 
TABLE 7.1 Countries involved in the third and fourth Arab Barometer survey

\begin{tabular}{lclc}
\hline & Third survey: 2012-2014 & \multicolumn{2}{c}{ Fourth survey: 2016-17 } \\
\hline Country & Sample & Country & Sample \\
\hline Egypt & 1195 & Egypt & 1200 \\
Jordan & 1795 & Jordan & 1500 \\
Iraq & 1215 & n.p. & n.p. \\
Lebanon & 1200 & Lebanon & 1500 \\
Palestine & 1171 & Palestine & 1199 \\
& & & 1200 \\
Algeria & 1220 & Algeria & 1200 \\
Morocco & 1116 & Morocco & 1200 \\
Tunisia & 1199 & Tunisia & \\
Kuwait & 1021 & & \\
Libya & 1247 & & \\
Sudan & 1200 & & \\
Yemen & 1200 & & \\
\hline
\end{tabular}

SOURCE: ARAB BAROMETER DATA

failed and new autocratic regimes have been established (Alkhatib, 2014; Ceyhun, 2017a, 2017b; Tavana. 2017). The hope of a real new course of political events has been scaled down, as well as the expectations of a more open pluralistic society (Rahman, 2016; Grinin et al., 2019).

\section{Religious Belonging and Personal Religiosity}

The wide majority of people interviewed in each Arabian country belongs to Islamic religion with the exception of the Lebanese, one third of which $(38 \%)$ are Christians and in small amount (7\%) Druse; also in Egypt and Palestine there is a small minority of Christian believers (4-5\%) mainly concentrated in some areas.

The same distribution is confirmed by the fourth Arab Barometer wave (applied in 2016) with a small, but significant, increase in Christians and other minorities, parts of which have been compelled to escape from Syria (Ceyhun, 2017c) (Table 7.2). 
TABLE 7.2 Religious belonging of representative samples interviewed in 2014 (3rd wave) and 2016 (4th wave)

\begin{tabular}{|c|c|c|c|c|c|c|c|c|c|c|c|c|}
\hline & \multicolumn{2}{|c|}{ Egypt } & \multicolumn{2}{|c|}{ Iraq } & \multicolumn{2}{|c|}{ Jordan } & \multicolumn{2}{|c|}{ Lebanon } & \multicolumn{2}{|c|}{ Palestine } & \multicolumn{2}{|c|}{ Total } \\
\hline & 2014 & 2016 & 2014 & 2016 & 2014 & 2016 & 2014 & 2016 & 2014 & 2016 & 2014 & 2016 \\
\hline Muslim & $94 \%$ & $96 \%$ & $100 \%$ & n.p. & $100 \%$ & $98 \%$ & n.p. & $60 \%$ & $96 \%$ & $97 \%$ & $91 \%$ & $87 \%$ \\
\hline Christian & $6 \%$ & $4 \%$ & $0 \%$ & n.p. & o\% & $2 \%$ & $38 \%$ & $33 \%$ & $4 \%$ & $3 \%$ & $9 \%$ & $11 \%$ \\
\hline Other & n.p. & n.p. & n.p. & n.p. & n.p. & n.p. & n.p. & $7 \%$ & n.p. & n.p. & n.p. & $2 \%$ \\
\hline Total & $100 \%$ & $100 \%$ & $100 \%$ & n.p. & $100 \%$ & $100 \%$ & $38 \%$ & $100 \%$ & $100 \%$ & $100 \%$ & $100 \%$ & $100 \%$ \\
\hline
\end{tabular}

It is only in the case of Lebanon that we have specific information on the religion composition of both the Islamic community -with half Sunnis and Scythians, who together represent $56 \%$ of the total sample ${ }^{1}$ - and of the Christian one that includes a high variety of denominations, mainly Maronite (25\%), Orthodox (7\%), Catholic (4\%), and Armenian (1\%). This empirical evidence documents the possibility of a real pluralistic coexistence among different religious and cultural identities, with the support of suitable political institutions.

According the sample composition of each country, the data commented below include the answers by both Islamic and not Islamic people, the large diffusion of Islamic faith and belonging in four out five countries (see $3^{\text {rd }}$ wave) offers the opportunity to make some comparisons among national differences about religion, civil law, politics, and democracy (Bréchon, 2018).

The diffuse sense of belonging to a specific religion is supported by a strong personal commitment, considering that:

- More than 90\% declare to be a "religious person", with the highest degree in Egypt and Jordan (94-95\%); two years later (2016), Egyptians and Jordanians confirm their primacy, while Lebanese drop 7 percentage points (Table 7.3);

- About $70 \%$ declare to pray regularly every day, with values under the average in Lebanon $(60 \%)$, where there are more unresponsive and indifferent people. These widespread attitudes register some changes in the fourth wave, growing up in Jordan (from $71 \%$ to $77 \%$ ) and decreasing in Egypt (from $69 \%$ to $56 \%$ ), Lebanon (from $60 \%$ to $50 \%$ ) and on the whole (from $70 \%$ to $65 \%$ ) (Table $7 \cdot 4$ );

1 In the 2016 survey Muslims represent $60 \%$ of the total interviewed, $46 \%$ of them Sunni and $54 \%$ Shia. 
TABLE 7.3 Do you consider yourself to be a religious person?

\begin{tabular}{lccccc}
\hline & Egypt & Jordan & Lebanon & Palestine & Total \\
\hline 2014 & $94 \%$ & $95 \%$ & $85 \%$ & $93 \%$ & $92 \%$ \\
2016 & $97 \%$ & $97 \%$ & $78 \%$ & $92 \%$ & $89 \%$ \\
\hline
\end{tabular}

SOURCE: AUTHOR'S ELABORATION ON ARAB BAROMETER DATA

TABLE 7.4 Do you pray daily?

\begin{tabular}{lccccc}
\hline & Egypt & Jordan & Lebanon & Palestine & Total \\
\hline 2014 & $69 \%$ & $71 \%$ & $60 \%$ & $77 \%$ & $70 \%$ \\
2016 & $56 \%$ & $77 \%$ & $50 \%$ & $75 \%$ & $65 \%$ \\
\hline
\end{tabular}

SOURCE: AUTHOR'S ELABORATION ON ARAB BAROMETER DATA

- $40 \%$ declare to take part regularly in weekly religious ceremonies, with higher percentages among Egyptians (67\%) and Jordanians (61\%), and lower percentages among Iraqis $(18 \%)$, for reasons that could be related to insecurity rather than religious disinterest. The irregular ceremony participation is more widespread among Palestinians who, from this point of view, appear to be more secularized. ${ }^{2}$

- The listening and the reading of the Koran (or the Bible) are more diffused, also in this case, among Egyptians (50\%) and Jordanians (49\%), thus confirming that they are the most faithful and assiduous people. According to the 2016 survey, this behavior declines in each country (especially in Lebanon with $20 \%$ vs $38 \%$ ) and, overall, attesting at $35 \%$ vs $42 \%$ (Table $7 \cdot 5$ ).

- The majority of interviewed (39\%) assert to apply effectively the teachings of the Prophet (Mahomet) in their daily life and therefore to be good Muslim; ${ }^{3}$ on the contrary, only a small minority ( $\left.3 \%\right)$ consider themselves as completely incoherent and faraway from Islamic commandments.

- It's interesting to underline the strong distance between the Palestinians' and the Lebanese' self-esteem regarding their religious commitment: the former are confident in $46 \%$ of the cases, while the latter only in $26 \%$.

2 This issue is absent in the 4 th wave survey.

3 This issue, too, is absent in the 4 th wave survey. 
TABLE 7.5 Do you always listen to or read the Quran/the Bible?

\begin{tabular}{lcccccc}
\hline & Egypt & Iraq & Jordan & Lebanon & Palestine & Total \\
\hline 2014 & $50 \%$ & $26 \%$ & $50 \%$ & $38 \%$ & $46 \%$ & $42.5 \%$ \\
2016 & $43 \%$ & n.a. & $41 \%$ & $20 \%$ & $40 \%$ & $35 \%$ \\
\hline
\end{tabular}

SOURCE: AUTHOR'S ELABORATION ON ARAB BAROMETER DATA

The "self-examination" requested to the interviewed regarding their understanding and their practice of the faith also includes an evaluation of their personal fidelity and coherence towards the teaching of Prophet Muhammed and an evaluation of the same topics from other believers with whom they are in touch.

Generally, the interviewed evaluate themselves as good testimony of the Prophet's teachings, with some kind of over-estimation and self-confidence: $39 \%$ declare to be "a good Muslim" and only $21 \%$ feel to be "not very" or "not at all" reliable.

The evaluations towards the others is decisively lower, because they are considered as "good" testimony only by $18 \%$ of the people and as "bad" by $37 \%$. The general results are differentiated among countries: Lebanese and Palestinians are particularly negative, while Egyptians are very optimistic and confident toward their fellow worshippers.

In summary, we may say that most interviewed have a high self-commitment to the faith they declare, which, in fact, has a great and direct influence on their everyday life (Spierings, 2018).

\section{$3 \quad$ Islam and Civil Law}

The relation among the norms ruling the religious community and the secular community has been (and still is) a largely discussed topic, ascribable synthetically- to the question of "secularity", i.e. the distinction among the religious and the civil spheres in the context of "pluralistic societies", very differentiated in every aspect (Jamal, 2018).

In Europe, the acquisition of this distinction is part of a long-lasting and dramatic historical process, started during the 14th century and proceeded until the 19th century. Indeed, the principle "cuius regio, eius religio" (during the Protestant and Catholic Reform) established the primacy of the religious beliefs of the rulers (kings or other chiefs) over the ruled people, with the 
consequent right to impose their own ideas and principles over the "mass", with an authoritarian approach.

What the European culture has considered for many centuries as obvious and mainstream is, however, not accepted inside the Islamic world. There, the distinction between religion and politics - established, from an ideal point of view, from Jesus Christ's sentence "Render to Caesar the things that are Caesar's, and to God the things that are God's"- has never taken root, both for doctrinal and social reasons.

Even if in some Arab Islamic countries secular political regimes arose during 2oth century, ${ }^{4}$ after the Khomeini revolution (1979) the cultural and political hegemony of religious chiefs grew newly up, with a consequent revival of political-religious conflicts in the whole Middle East, as in the emblematic case of Shia and Sunni regimes (see Chapter 5 ).

With the complicity of many economic, national, ethnic cleavages inside the Arab Islamic countries, the religious identities have re-obtained the central role of "cement of the society"; therefore, it is not surprising that religious norms have become the central point of every kind of (moral, legal, economic, political) value and rule. The open question is in which way the coexistence of different religious believers may be regulated, respecting differences and promoting freedom of speech and expression.

According our empirical data, ${ }^{5}$ most of the people interviewed in 2012-2014 have assigned to Islamic laws the primacy over popular willing, denying essential value to democratic procedures. This approach is mainly diffused in Jordan, where $40 \%$ of the people strongly agree with the idea that "The Government and the Parliament should enact laws in accordance with the Islamic law"; the same idea is more cautiously supported by Palestinians (30\%), Egyptians $(26 \%)$, and Iraqis $(16 \%)$, but if we add the partial agreement ("somewhat agree"), the consensus reaches $65^{-80} \%$. This idea is firmly refused by the Lebanese, who prefer the secular primacy of popular consensus.

The opposite idea that "The Government and the Parliament should enact laws in accordance with people's wishes" reaches less consensus ( $20 \%$ on average), even if, in total, agreements $(52 \%)$ always overcome disagreements $(42 \%)$. It is important to underline that the Lebanese people confirm their support to the principle of democratic consensus $(43 \%)$, rejecting "strongly or somewhat" $(82 \%)$ the principle of Islamic hegemony. In other words, many

4 See the regime of Nasser, Gamal Abdel (1918-1970), President of Egypt from 1954 to 1970 and the role of Bath party, in Iraq, at the base of the regime of Saddam Hussein (1937-2006), lasted from 1979 to 2006, and supporter, in Syria, of the Arab Republic since 1963. In 1970, the power was achieved by the Assad dynasty.

5 The data here discussed have been collected only in the third Arab Barometer survey (2012-2014). 
Lebanese people support the distinction between religion and politics according to the secular approach (see below, §4).

The intermediate solution that tries to combine both the previous principles -assigning different priorities to religious or secular principles, according to the questions to face ${ }^{6}$ gets the maximum consensus among Iraqis $(34 \%)$ and Egyptians (33\%), followed by Jordanians $(26 \%)$ and Palestinian $(16 \%)$, who, as we noted before, largely support the monocratic solutions. The dissent of the Lebanese towards the religious principle is confirmed also by means of this variable, considering that $52 \%$ of them reject a limited intrusion of religious norms into politics.

The same ideological tendencies get reinforcement when people react to the question of criminal laws, i.e. the branch of law that produces heavy restrictions to personal freedom in the event of behaviors considered as dangerous for the members of society. The most confessional are, again, Jordanians $(51 \%)$, followed by Palestinians (37\%), Egyptians (31\%) and Iraqis (28\%). Lebanese people confirm their previous attitudes, supporting mainly $(60 \%)$ the non-religious perspective.

Similar preferences emerge when people refer to the primacy of Islamic laws in the contest of family relations: $60 \%$ of Jordanians strongly agree with the idea that "The Government and the Parliament should enact personal status laws (marriage, divorce) in accordance with the Islamic law", while only $12 \%$ of Lebanese accept this hypothesis.

Finally, the fundamentalist approach is, once again, clear when people answer to the sentence "The Government and the Parliament should enact inheritance laws in accordance with the Islamic law" by referring directly to tradition and Islamic norms: Jordanians put themselves at the top (63\%), followed by Egyptians $(56 \%)$, Palestinians $(50 \%)$ and Iraqis $(49 \%)$. Lebanese are at the bottom, with a very little agreement (14\%).

All the answers on these topics have been transformed in a synthetic index named Islam Law Conformity Index (ISLC Index) finalized to check how important the Islamic law must (or must not) be in producing and supporting the decision of both Government and Parliament (Table 7.6). ${ }^{7}$

6 See the following sentence: "To what extent do you agree or disagree with each of the following principles in the enactment of your country's laws and regulations? The Government and the parliament should enact penal laws in accordance with the Islamic law".

7 For calculating this index, the original variables (q605.1 to q605.6) have been recoded giving:

- Highest score to options that indicate unconditioned agreement with the primacy of Koranic law in every Government or Parliament decision (see q605.2, q605.4, q605.5, q605.6);

- Middle score to options that indicate a conditioned agreement with the primacy of Koranic law in every Government or Parliament decision (see q605.1); 
TABLE 7.6 Islam Law Conformity Index by sex and age (score: $\min =1, \max =6)$

\begin{tabular}{lcccccc}
\hline \multicolumn{1}{c}{} & \multicolumn{2}{c}{ Sex } & \multicolumn{3}{c}{ Age } \\
& Total & Male & Female & Up to 29 & $\mathbf{3 0 - 4 5}$ & $\begin{array}{r}\mathbf{4 6} \text { and } \\
\text { more }\end{array}$ \\
& & & & & & \\
\hline Egypt & 4.30 & 4.32 & 4.28 & 4.03 & 4.42 & 4.52 \\
Iraq & 4.28 & 4.27 & 4.28 & 4.22 & 4.33 & 4.30 \\
Jordan & 4.51 & 4.43 & 4.61 & 4.55 & 4.48 & 4.51 \\
Lebanon & 2.43 & 2.41 & 2.45 & 2.71 & 2.56 & 2.09 \\
Palestine & 4.36 & 4.27 & 4.45 & 4.45 & 4.32 & 4.30 \\
Total & 4.02 & 3.99 & 4.04 & 4.06 & 4.11 & 3.83 \\
\hline
\end{tabular}

SOURCE: AUTHOR'S ELABORATION ON ARAB BAROMETER DATA

In a scale from 1 to 6 , the average score reached by all interviewed is 4.02 , with higher values in Jordan (4.51) and lower ones in Lebanon (2.43) confirming a well know trend.

In Jordan and Palestine, the IS LC Index is higher among young people (up to 29 years old: 4.55 and 4.45), who look more radical, while in Egypt and Iraq this Index is higher among the elderly $(4.52,4.30)$. The generational change goes in opposite directions in the single countries: it increases traditionalism in Jordan and Palestine, but it contributes to modernization in Egypt and Iraq. Lebanon keeps its originality: it is less sensible to Islamic traditionalism, owing to the relevant presence of Christians; nevertheless the (low) Islamic traditionalism is more attractive for young people (Robbins, 2017).

\section{$4 \quad$ The Influence of Shari'a}

Inside these general trends, largely approving the cultural leadership of Islam in the field of moral and legal regulation of society, specific attention should be paid to the supporters of the direct application of Shari'a in all private and public spheres - as it is recommended by the radical loyalty to Islamic tradition

- Lowest score to options indicated in the unique variable that establishes no conformity to Koranic law (see q605.1). 
and by the fundamentalist political movements (Bell et al., 2013; Ciftci etal., 2018).

Our reference is mainly to the third edition of Arab Barometer employing more questions ${ }^{8}$ finalized to understand:

- The expected role of Shari'a in laws regulating marriage and divorce;

- The perception of the effective influence of Shari'a on the laws of each country;

- The divine or human foundation of Sharia according the theological and cultural debate developed in the last years inside Islam;

- The (effective or potential) conflict among the western vision of democracy and the Islam teachings on the same question;

- The limited concession of political rights to non-Islamic minorities;

- The contrast among the economic Islamic teachings and the application of interests by the bank system.

The idea that Shari'a must regulate marriage and divorce is supported by $69 \%$, mainly in Egypt and Palestine, where people appear to be more orthodox and radical. The existence of a direct relationship (strong or not) among Sharica and ordinary laws is perceived by $53 \%$ of the interviewed, with percentages above 60 points in Iraq, Jordan, Palestine, but very low in Lebanon (23\%).

Except for the Lebanon case -where Shari'a influence is limited and, therefore, the opinions expressed by the interviewed probably reflect the reality-it is not easy to distinguish if the evaluations by people reflect a deed (judgment of fact) or a wish (judgment of value).

This ambivalence cannot be observed in the 2016 survey, where people have answered to a clearer question: $33 \%$ would like the laws in their countries to be entirely or, mostly, based on the Shari'a. Then, $41 \%$ would like an equally balanced system (based on Shari'a and on the will of the people). Finally, only $12 \%$ indicate the primacy of the people will, according the rules of liberal-democratic systems. The preference for Shari'a overcomes that for democracy, mainly in Palestine $(50 \%$ vs $11 \%)$ and Jordan ( $44 \%$ vs $4 \%)$, in open opposition to Lebanese attitudes (66\% in favor of popular will) (Table 7.7).

According to a fundamentalist interpretation, the primacy of Sharia gains its support by its divine origin and, thus, it cannot be reformed or disregarded; this approach produces radical consequences, not only at theological level, but

8 In the 2016 survey, this issue was not discussed with the same extension, even if some topics had been dealt with. 
TABLE 7.7 Which of the following statements is the closest to your point of view? Laws of our country should be based...

Fourth Entirely on Mostly on Equally on Mostly on Entirely on Do not Decline to Total wave: 2016 the Shari'a the Shari'a Shari'a and the will of the will of know answer the will of the people the people the people

\begin{tabular}{|c|c|c|c|c|c|c|c|c|}
\hline Egypt & $23 \%$ & $10 \%$ & $50 \%$ & $4 \%$ & $7 \%$ & $4 \%$ & $0 \%$ & $100 \%$ \\
\hline Jordan & $32 \%$ & $11 \%$ & $51 \%$ & $2 \%$ & $2 \%$ & $2 \%$ & $0 \%$ & $100 \%$ \\
\hline Lebanon & $3 \%$ & $4 \%$ & $27 \%$ & $22 \%$ & $44 \%$ & $1 \%$ & o\% & $100 \%$ \\
\hline Palestine & $41 \%$ & $10 \%$ & $36 \%$ & $3 \%$ & $8 \%$ & $2 \%$ & $0 \%$ & $100 \%$ \\
\hline Total & $24 \%$ & $9 \%$ & $41 \%$ & $8 \%$ & $16 \%$ & $2 \%$ & $0 \%$ & $100 \%$ \\
\hline
\end{tabular}

also at a social and political one, therefore generating difficulties as far as a pluralistic and tolerant coexistence is concerned.

Two interviewed out of three extensively agree with the idea that Shari'a is "Word of God", with higher consensus among Palestinians (76\%) and Jordanians $(71 \%)$, but under average percentages among Lebanese people (43\%), owing to the presence of many non-Muslim people.

The spread of the ideological radicalism may be further estimated through three other items creating a large debate among Islamic theologians and lawyers and concerning democracy, political rights, as well as the bank system.

On average, $26 \%$ think that democracy is a system that contradicts the teaching of Islam. This attitude is more diffused among Jordanians (strongly + somewhat: $37 \%)$, Palestinians (31\%) and Lebanese (30\%) because the Muslim part of the population is highly concentrated on this position. On the contrary, it is less supported by Egyptians (6\%), directly involved -in the same periodin a democratic experiment.

These orientations have been confirmed also in the 4th Arab Barometer wave (agreement: $26 \%$ vs $24 \%$ ), but with very significant changes in Jordan and Egypt, respectively more and less supportive towards the compatibility Islam-democracy (Jordan: 79\% vs 54\%; Egypt 71\% vs 77\%) (Table 7.8).

Strictly connected to the democratic question is the idea (sometimes, unfortunately, corresponding to a practice) that in a Muslim country, non-Muslims should enjoy less political rights than Muslims: $21 \%$ agree, strongly or somewhat, with this hypothesis. Compared with other topics, the consensus is low: only Jordanians exceed the average ( $39 \%$ vs $21 \%$ ) while $65 \%$ of Lebanese and $46 \%$ of Egyptians strongly refuse it. 
TABLE 7.8 Compatibility of Western democracy with Islam teachings: agreement ${ }^{\mathrm{a}}$

\begin{tabular}{lcccc}
\hline & $\begin{array}{c}\text { Agree } \\
\text { (strongly or } \\
\text { somewhat) }\end{array}$ & \multicolumn{2}{c}{$\begin{array}{c}\text { Disagree } \\
\text { (strongly or } \\
\text { somewhat) }\end{array}$} \\
\hline & $\mathbf{2 0 1 4}$ & $\mathbf{2 0 1 6}$ & $\mathbf{2 0 1 4}$ & $\mathbf{2 0 1 6}$ \\
\hline Egypt & $5 \%$ & $12 \%$ & $77 \%$ & $71 \%$ \\
Iraq & $23 \%$ & $\mathrm{n} / \mathrm{a}$ & $55 \%$ & $\mathrm{n} / \mathrm{a}$ \\
Jordan & $37 \%$ & $18 \%$ & $54 \%$ & $79 \%$ \\
Lebanon & $30 \%$ & $34 \%$ & $61 \%$ & $60 \%$ \\
Palestine & $31 \%$ & $30 \%$ & $66 \%$ & $64 \%$ \\
Total & $26 \%$ & $24 \%$ & $65 \%$ & $69 \%$ \\
\hline
\end{tabular}

SOURCE: AUTHOR'S ELABORATION ON ARAB BAROMETER DATA

a The formulation of the question presents some differences in the two Arab Barometer waves. In the 2014 wave, the question was "Democracy is a system that contradicts the teachings of Islam"; in the 2016 wave, the question was "Democracy is a Western form of Government that is not compatible with Islam".

The agreement goes up, once again, when people answer to the contrast among teachings of Islam and the charging of interest applied by banks: $86 \%$ of Jordanians and $81 \%$ of Palestinians support this interpretation, but only $53 \%$ of Egyptians and Iraqis share the same sentiment. Submitted two years later, the same question has obtained, on average, an increasing agreement $(75 \% v s$ $69 \%)$, due principally to Lebanese answers ( $77 \%$ vs $62 \%)$, mainly to engage in controversy with Islamic people than for ideological consensus (Table 7.9).

In conclusion, we must register a very large consensus towards central topics of the Islamic doctrine, which, on many occasions, have relevant political consequences. Even if the majority of people does not directly support the radical Islamic groups that propose to apply Sharica "sine glossa" to all the aspects of social and political life, these groups receive, at least indirectly, an ideological legitimization that is difficult to deny.

On the basis of the previous variables, we may elaborate an "Islamic Traditionalism Index" (IST Index) that reaches its maximum agreement (73\%) at the maximum level of intensity. ${ }^{9}$ This result acquires an emblematic importance when compared between each country: the ideological traditionalism reaches its (relatively) higher degree in Egypt (average score 2.76 on a scale 1 to 3 ) and

9 By grouping the scores of this cardinal measure at three levels (low, middle, high), the large majority appears to be very traditionalist. 
TABLE 7.9 Banks charging interest contradict the teachings of Islam

\begin{tabular}{|c|c|c|c|c|}
\hline & \multicolumn{2}{|c|}{$\begin{array}{c}\text { Agree } \\
\text { (strongly or } \\
\text { somewhat) }\end{array}$} & \multicolumn{2}{|c|}{$\begin{array}{c}\text { Disagree } \\
\text { (strongly or } \\
\text { omewhat) }\end{array}$} \\
\hline & 2014 & 2016 & 2014 & 2016 \\
\hline Egypt & $55 \%$ & $53 \%$ & $21 \%$ & $30 \%$ \\
\hline Iraq & $54 \%$ & $\mathrm{n} / \mathrm{a}$ & $29 \%$ & $\mathrm{n} / \mathrm{a}$ \\
\hline Jordan & $86 \%$ & $85 \%$ & $9 \%$ & $13 \%$ \\
\hline Lebanon & $62 \%$ & $77 \%$ & $25 \%$ & $19 \%$ \\
\hline Palestine & $81 \%$ & $81 \%$ & $15 \%$ & $16 \%$ \\
\hline Total & $69 \%$ & $75 \%$ & $19 \%$ & $19 \%$ \\
\hline
\end{tabular}

SOURCE: AUTHOR'S ELABORATION ON ARAB BAROMETER DATA

in Palestine (2.73), while its minimum degree is registered in Lebanon (2.12). By comparing the totals, we can observe that there are no significant differences among male and female sub-groups (2.64). The same trend is registered in each country, with the only exception of Lebanon, where women overcome man in the level of traditionalism - which, in any case, is lower than in other countries.

The orientations of the three different age groups are practically similar, but it is interesting to note that in Egypt, Palestine and Lebanon, the Islam traditionalism is a peculiarity of the youngsters, with probably not positive consequences on social coexistence (Table 7.10).

In opposition to the Islamic Traditionalism Index -synonymous of strong conservativism - we have elaborated an index of modernization, named "Islam Openness Index" (ISO Index), on the basis of three variables collecting positive agreement towards:

a) gender-mixed education in Universities;

b) the possibility for women to wear modest clothes without needing to wear hijab;

c) the right of religious minorities to practice their religion freely. ${ }^{10}$

10 From the calculus of the Index, we have excluded the variable "To what extent do you agree with each of these statements?” Difference and variation between Islamic scholars, with regard to their interpretation of religious matters, is a good thing (q6082) because, by 
TABLE 7.10 Islamic Traditionalism Index by sex and age ( $\operatorname{score:~} \min =1, \max =3$ )

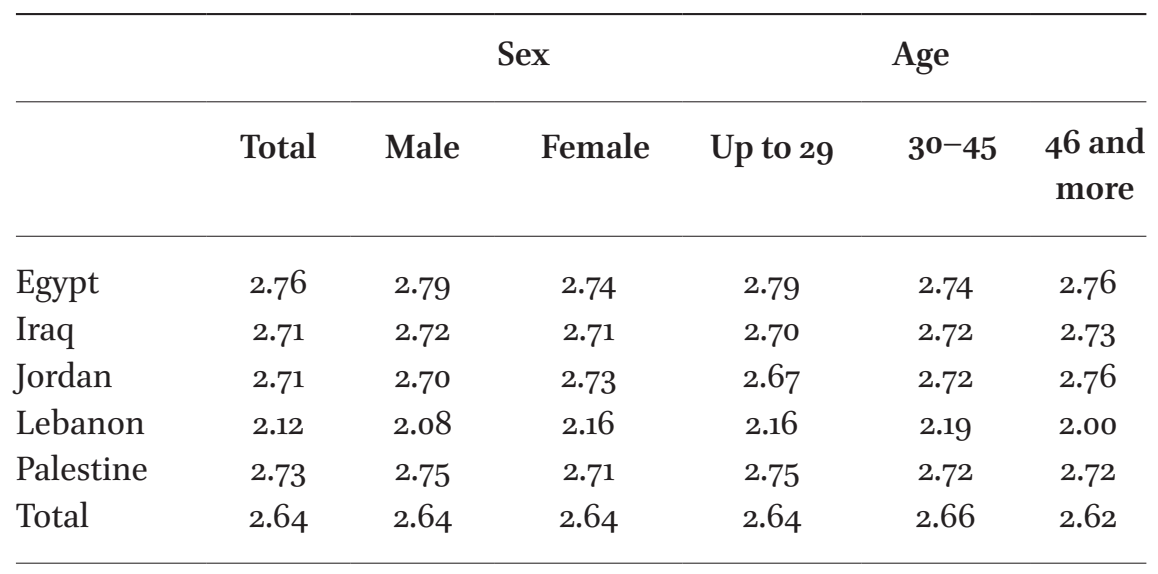

SOURCE: AUTHOR'S ELABORATION ON ARAB BAROMETER DATA

The majority ( $63 \%)$ of the whole sample agrees (strongly or somewhat) that, in universities, young women and men could study together, but the differences among countries are very wide (Robbins, Thomas, 2018): the agreement of Egyptians (49\%), Palestinians (55\%) and Jordanians (57\%) is under average, while $94 \%$ of the Lebanese openly support this issue (Table 7.11).

The substitution of the hijab with other modest clothes receives, at a general level, less consensus than before ( $54 \%$ vs $63 \%)$, because $65 \%$ of Iraqi, and $52 \%$ of Palestinians are mainly adverse (Table 7.12 ).

The right to practice freely own religion meets a quite universalistic support ( $86 \%$ agree strongly or somewhat) but in Jordan $(79 \%)$, the consensus is under the average.

Despite what we could expect on the basis of Islamic Traditionalism Index (very high in $73 \%$ of the cases), people who are not open-minded are a minority $(25 \%)$, while people with a positive openness reach $36 \%$. In a scale from 1 to 4 , the most open-minded country is Lebanon ( 3.30 scores), followed by Jordan (2.93) and Egypt (2.90): on the contrary, the countries less open to the innovations are Iraq (2.70) followed by Palestine (2.83) (Table 7.13). Gender differences are generally not relevant, except in Jordan, where women are more innovative than men; young people are not more open than the elderly, as in Egypt and Lebanon.

applying factor analysis to the empty array (q6071 to q6073 and q6082 to q6087), it turns out to be not pertinent enough. 
TABLE 7.11 Gender mixed education should be allowed in universities ${ }^{\mathrm{a}}$

\begin{tabular}{|c|c|c|c|c|}
\hline & \multicolumn{2}{|c|}{$\begin{array}{c}\text { Agree } \\
\text { (strongly or } \\
\text { somewhat) }\end{array}$} & \multicolumn{2}{|c|}{$\begin{array}{c}\text { Disagree } \\
\text { (strongly or } \\
\text { somewhat) }\end{array}$} \\
\hline & 2014 & 2016 & 2014 & 2016 \\
\hline Egypt & $49 \%$ & $64 \%$ & $41 \%$ & $33 \%$ \\
\hline Iraq & $66 \%$ & n.p. & $30 \%$ & n.p. \\
\hline Jordan & $57 \%$ & $56 \%$ & $38 \%$ & $44 \%$ \\
\hline Lebanon & $94 \%$ & $90 \%$ & $5 \%$ & $9 \%$ \\
\hline Palestine & $55 \%$ & $56 \%$ & $44 \%$ & $43 \%$ \\
\hline Total & $64 \%$ & $67 \%$ & $32 \%$ & $31 \%$ \\
\hline
\end{tabular}

SOURCE: AUTHOR'S ELABORATION ON ARAB BAROMETER DATA

a In the 2017 wave, the question was "Is it acceptable, in Islam, for male and female university students to attend classes together?".

TABLE 7.12 Women should wear modest clothes without needing to wear hijab

\begin{tabular}{lcccc}
\hline & \multicolumn{2}{c}{$\begin{array}{c}\text { Agree } \\
\text { (strongly or } \\
\text { somewhat) }\end{array}$} & $\begin{array}{c}\text { Disagree } \\
\text { (strongly or somewhat) }\end{array}$ \\
& $\mathbf{2 0 1 4}$ & $\mathbf{2 0 1 7}$ & $\mathbf{2 0 1 4}$ & $\mathbf{2 0 1 7}$ \\
\hline Egypt & $50 \%$ & $51 \%$ & $41 \%$ & $46 \%$ \\
Iraq & $31 \%$ & n.p. & $66 \%$ & n.p. \\
Jordan & $61 \%$ & $49 \%$ & $34 \%$ & $51 \%$ \\
Lebanon & $78 \%$ & $68 \%$ & $20 \%$ & $31 \%$ \\
Palestine & $47 \%$ & $44 \%$ & $52 \%$ & $56 \%$ \\
Total & $54 \%$ & $54 \%$ & $42 \%$ & $45 \%$ \\
\hline
\end{tabular}

SOURCE: AUTHOR'S ELABORATION ON ARAB BAROMETER DATA

a In the 2017 wave the question was "A woman should dress modestly, but Islam does not require that she wears a hijab".

The indexes that we have constructed to reduce the complexity of the information present direct (and statistically significant) correlations among them, 
TABLE 7.13 Islam Openness Index by sex and age (score: $\min =1, \max =4)$

\begin{tabular}{lcccccc}
\hline & \multicolumn{3}{c}{ Sex } & \multicolumn{3}{c}{ Age } \\
& Total & Male & Female & Up to 29 & $\mathbf{3 0 - 4 5}$ & $\begin{array}{c}\mathbf{4 6} \text { and } \\
\text { more }\end{array}$ \\
& & & & & & \\
\hline Egypt & 2.90 & 2.92 & 2.88 & 2.86 & 2.91 & 2.95 \\
Iraq & 2.70 & 2.73 & 2.67 & 2.72 & 2.71 & 2.65 \\
Jordan & 2.93 & 2.88 & 2.98 & 2.96 & 2.93 & 2.88 \\
Lebanon & 3.30 & 3.29 & 3.31 & 3.25 & 3.27 & 3.36 \\
Palestine & 2.83 & 2.84 & 2.83 & 2.81 & 2.86 & 2.82 \\
Total & 2.93 & 2.92 & 2.94 & 2.91 & 2.93 & 2.97 \\
\hline
\end{tabular}

SOURCE: AUTHOR'S ELABORATION ON ARAB BAROMETER DATA

which are sometimes positive and sometimes negative, as in the case of Islamic Traditionalism Index and of Islam Openness Index. ${ }^{11}$

Thanks to these two indexes, it is possible to identify different ideological subgroups inside Islamic people that create an Islam pluralistic typology, not always easy to interpreter in an ideal-type way. The conceptual boundaries among them are sometimes undetermined by an empirical point of view, owing to some contradictory overlapping, as in the case of 1,437 interviewed ( $23 \%$ of total sample) who reach a high score in both the indexes (Table 7.14).

The most numerous group is represented by "opportunist people", i.e. very conformist, but hesitant and open to some changes $(27 \%)$, followed by those who may be defined as "contradictory people" (23\%), as they declare to be very traditionalist as well as very open to some changes, and the effective radical extremist, i.e. very traditional and very close $(22 \%)$. All the other groups are not very consistent and are composed of: "revisionist" (7\%) (traditionalist, but with much openness); "moderate people" (7\%) (traditionalist and openminded at a medium level); "conservative people" (5\%) (traditionalist and less open); reformist ( $5 \%$ ) (not that traditionalist and very open); in talks people $(2 \%)$ (not that traditionalist and quite open); apathetic (1\%) (neither traditionalist nor open) (Table 7.15).

11 The highest positive correlation emerges among Islamic Traditionalism Index and Islam Law Conformity Index ( $\mathrm{r}$ coefficient = .448); negative correlations emerge, on the contrary, among Islam Openness Index (that indicates distancing from a rigid orthodoxy) and the other ones, respectively with r. coefficient -.190 and -.304. 
TABLE 7.14 Islamic Traditionalism Index (recorded in three levels) (IST INDEx R3) by Islam Openness Index (recorded in three levels) (ISO INDEX R3)

ISO INDEX R3

\begin{tabular}{lcccc}
\hline IST INDEX R3 & Low & Medium & High & Total \\
\hline low & 89 & 136 & 294 & 519 \\
medium & 305 & 438 & 446 & 1189 \\
high & 1398 & 1667 & 1437 & 4502 \\
Total & 1792 & 2241 & 2177 & 6210 \\
\hline
\end{tabular}

SOURCE: AUTHOR'S ELABORATION ON ARAB BAROMETER DATA

TABLE 7.15 Islam pluralistic typology

\begin{tabular}{lccccccc}
\hline \multicolumn{5}{c}{ Country } & & \multicolumn{2}{c}{ Total } \\
\hline & Egypt & Iraq & Jordan & Lebanon & Palestine & $\%$ & $\mathbf{N}$. \\
\hline Opportunist & $28 \%$ & $34 \%$ & $26 \%$ & $12 \%$ & $32 \%$ & $27 \%$ & 1667 \\
Contradictory & $25 \%$ & $13 \%$ & $29 \%$ & $27 \%$ & $20 \%$ & $23 \%$ & 1437 \\
Radical & $29 \%$ & $29 \%$ & $21 \%$ & $5 \%$ & $27 \%$ & $23 \%$ & 1398 \\
Revisionist & $6 \%$ & $4 \%$ & $8 \%$ & $14 \%$ & $6 \%$ & $7 \%$ & 446 \\
Moderate & $6 \%$ & $9 \%$ & $7 \%$ & $7 \%$ & $6 \%$ & $7 \%$ & 438 \\
Conservative & $2 \%$ & $8 \%$ & $6 \%$ & $3 \%$ & $4 \%$ & $5 \%$ & 305 \\
Reformist & $3 \%$ & $1 \%$ & $1 \%$ & $22 \%$ & $3 \%$ & $5 \%$ & 294 \\
In talks & $1 \%$ & $2 \%$ & $1 \%$ & $7 \%$ & $2 \%$ & $2 \%$ & 136 \\
Apathetic & $0 \%$ & $2 \%$ & $1 \%$ & $3 \%$ & $1 \%$ & $1 \%$ & 89 \\
Total & $100 \%$ & $100 \%$ & $100 \%$ & $100 \%$ & $100 \%$ & $100 \%$ & 6210 \\
\hline
\end{tabular}

SOURCE: AUTHOR'S ELABORATION ON ARAB BAROMETER DATA

The statistical distribution of all these groups inside each country allows to find some new peculiarities, together with some confirmations: in Egypt, Iraq, and Palestine the diffusion of extreme radicalism is confirmed, but positive signals come from the presence of contradictory openness in favor of the abolition of some "taboos".

The contradictory orientations indicated by empirical results reproduce, in a reliable way, the ideological and political uncertainty that has been long characterizing the Islamic countries of the Middle East and their difficulties to 
promote a transition towards a more tolerant coexistence between majority and minority groups (identified mainly by their religious beliefs) among which Christians are prevalent. ${ }^{12}$

The comparisons by sex and age show less differences inside each ideological group, which are characterized more for their radicalism than for their reformism. Approach

In order to understand the cultural trends that are developing in Arab societies, it is important to deal with the relations among religion and politics, by using as reference the polarity "dependence-autonomy" of politics, according to a well-known Western intellectual approach. Without accepting the interpretative frame of the French "laïcité" -based on a radical separation between religion and politics, which in fact aims to submit religion to politics- we assume the distinction among "fundamentalism" (direct interference of religious authorities on politics) and "secularism" (autonomy of politics from religion's influence).

Among the variables regarding this issue, four of them measure the agreement towards a direct interference of religion in the political arena, while the other two measure the opposite vision; on the basis of these variables, we have elaborated two concise indexes, named, respectively "Secular Politics Index" (SECPOL) and "Fundamentalism Index" (FUNPOL).

In a scale from 1 to 4 , the total average score of the Secular Politics Index overcomes point 3 , documenting -as we will read below- a middle-high disposition to defend the autonomy of politics (and politicians) from religious leaders (imams, preachers, priests). This disposition is less appreciated in Palestine (2.90), but strongly shared in Lebanon (3.62), where each variable reaches the highest average score.

By grouping the scores of Secular Politics Index in three modalities (low, middle, high), most interviewed (53\%) put themselves at the highest level of agreement, with $82 \%$ of the Lebanese $v s 29 \%$ of Palestinians (Table 7.16).

Gender and age differences are very limited, confirming a large ideological homogeneity and conformism (Table 7.17).

12 The contradictory attitudes are less diffused in Iraq (13\%) where opportunism is more extensive $(34 \%)$, while Lebanon confirms its peculiarity with a lot of "reformist" $(22 \%)$ and "revisionist" (14\%). 


\section{Country}

\begin{tabular}{lcccccc}
\hline & Egypt & Iraq & Jordan & Lebanon & Palestine & Total \\
\hline Low & $15 \%$ & $17 \%$ & $21 \%$ & $7 \%$ & $26 \%$ & $17 \%$ \\
Middle & $27 \%$ & $35 \%$ & $31 \%$ & $11 \%$ & $45 \%$ & $30 \%$ \\
High & $58 \%$ & $48 \%$ & $48 \%$ & $82 \%$ & $29 \%$ & $53 \%$ \\
Total & $100 \%$ & $100 \%$ & $100 \%$ & $100 \%$ & $100 \%$ & $100 \%$ \\
\hline
\end{tabular}

SOURCE: AUTHOR'S ELABORATION ON ARAB BAROMETER DATA

TABLE 7.17 Secular Politics Index by sex and age (scores: $\min =1, \max =4$ )

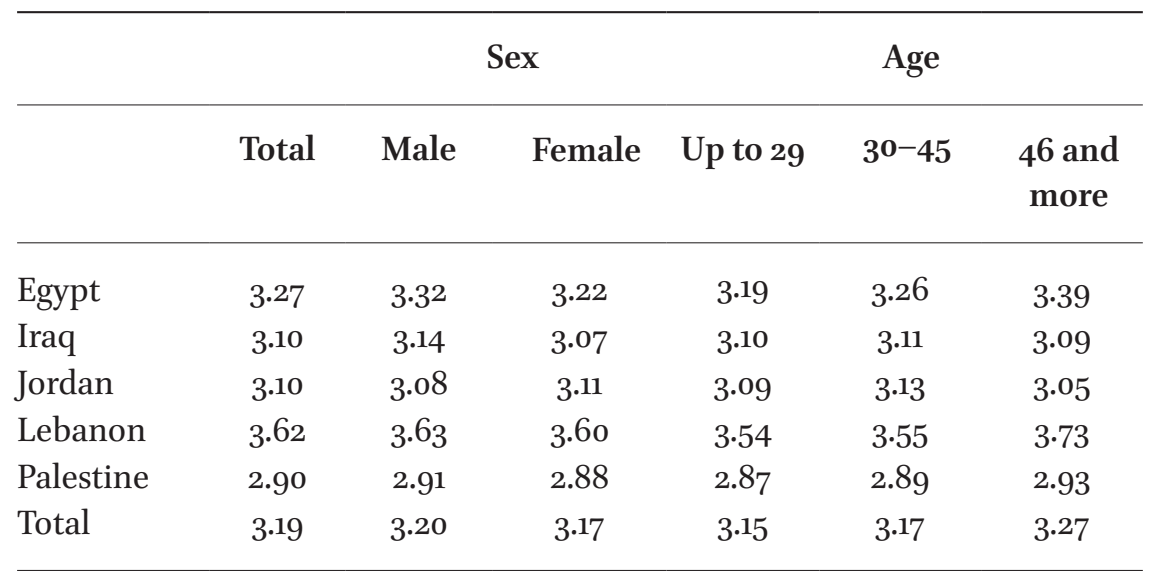

SOURCE: AUTHOR'S ELABORATION ON ARAB BAROMETER DATA

The total average score of the Fundamentalism Index is attested at point 2; this result documents a low disposition for the direct control of political organizations from religious authorities. This attitude reaches the highest score in Jordan (2.52), Palestine (2.44), Iraq (2.43), and the lowest one in Lebanon (1.38) confirming the specificity of this country (Table 7.18).

By grouping, also in this case, the scores of the Fundamentalism Index in three levels, it emerges that $56 \%$ of the people put themselves at a low level, with a primacy of the Lebanese (90\%) and the last place of Jordanians (39\%) (Table 7.19).

The comparisons by gender underline, in each country, that women are more traditionalist than men; fundamentalism is also more diffuse among the 
TABLE 7.18 Fundamentalism Index by sex and age (scores: $\min =1, \max =4$ )

\begin{tabular}{lcccccc}
\hline & \multicolumn{3}{c}{ Sex } & \multicolumn{3}{c}{ Age } \\
& Total & Male & Female & Up to 29 & $\mathbf{3 0 - 4 5}$ & $\begin{array}{r}\mathbf{4 6} \text { and } \\
\text { more }\end{array}$ \\
& & & & & & \\
\hline Egypt & 1.99 & 1.90 & 2.08 & 1.92 & 1.98 & 2.09 \\
Iraq & 2.43 & 2.38 & 2.49 & 2.36 & 2.49 & 2.47 \\
Jordan & 2.52 & 2.49 & 2.55 & 2.47 & 2.56 & 2.53 \\
Lebanon & 1.38 & 1.37 & 1.39 & 1.45 & 1.44 & 1.26 \\
Palestine & 2.44 & 2.37 & 2.50 & 2.46 & 2.44 & 2.40 \\
Total & 2.18 & 2.14 & 2.22 & 2.18 & 2.24 & 2.10 \\
\hline
\end{tabular}

SOURCE: AUTHOR'S ELABORATION ON ARAB BAROMETER DATA

TABLE 7.19 Fundamentalism Index $\mathrm{R}_{3}$

\begin{tabular}{lcccccc}
\hline & Egypt & Iraq & Jordan & Lebanon & Palestine & Total \\
\hline Low & $70 \%$ & $44 \%$ & $39 \%$ & $90 \%$ & $44 \%$ & $56 \%$ \\
Middle & $16 \%$ & $23 \%$ & $20 \%$ & $5 \%$ & $24 \%$ & $18 \%$ \\
High & $14 \%$ & $33 \%$ & $40 \%$ & $5 \%$ & $33 \%$ & $26 \%$ \\
Total & $100 \%$ & $100 \%$ & $100 \%$ & $100 \%$ & $100 \%$ & $100 \%$ \\
\hline
\end{tabular}

SOURCE: AUTHOR'S ELABORATION ON ARAB BAROMETER DATA

elderly, except in Lebanon, where they lived the dramatic ethno-religious conflict during the 70 s and the 8 os of the past century (Table 7.20).

The secular or fundamentalist attitudes toward politics are directly related to the consensus towards secular or religious political parties in each country, which has been evaluated, too. In partial contradiction with the opinions registered through the Secular Politics Index, the majority of the interviewed (49\%) express their (strong plus positive) preferences in favor of the religious political parties, while only $30 \%$ disagree with this eventuality. As usual, the citizens of Palestine and Jordan opt for a fundamentalist approach (supported by $67 \%$ and $59 \%$ of the people), while the citizens of Lebanon mainly adopt a secular approach $(67 \%)$ (Table 7.20$)$. 
TABLE 7.20 Religious - Not religious political party agreement

\section{Egypt Iraq Jordan Lebanon Palestine Total}

\begin{tabular}{|c|c|c|c|c|c|}
\hline $\begin{array}{l}\text { Strong preference } \\
\text { for a religious political } \\
\text { party }\end{array}$ & $26 \%$ & $20 \%$ & $35 \%$ & $8 \%$ & $43 \%$ \\
\hline $\begin{array}{l}\text { Preference for a } \\
\text { religious political } \\
\text { party }\end{array}$ & $19 \%$ & $35 \%$ & $24 \%$ & $9 \%$ & $24 \%$ \\
\hline $\begin{array}{l}\text { Preference for a not } \\
\text { religious political } \\
\text { party }\end{array}$ & $27 \%$ & $17 \%$ & $10 \%$ & $27 \%$ & $14 \%$ \\
\hline $\begin{array}{l}\text { Strong preference for a } \\
\text { not religious political } \\
\text { party }\end{array}$ & $12 \%$ & $4 \%$ & $2 \%$ & $39 \%$ & $5 \%$ \\
\hline $\begin{array}{l}\text { Do not agree with } \\
\text { either sentence }\end{array}$ & $16 \%$ & $24 \%$ & $30 \%$ & $16 \%$ & $14 \%$ \\
\hline tal & $100 \%$ & $100 \%$ & $100 \%$ & $100 \%$ & $100 \%$ \\
\hline
\end{tabular}

SOURCE: AUTHOR'S ELABORATION ON ARAB BAROMETER DATA

Some final evaluations arise from the correlation coefficients between the indexes built during our comparative analysis ${ }^{13}$ and from the frequencies of the indexes grouped in three classes.

As we could expect, the preferences for the autonomy of politics from religious authorities (see Secular Politics Index) are positively correlated with the Islam Openness Index $(\mathrm{r}=.364)$ and negatively correlated with the Fundamentalism Index ( $\mathrm{r}=-.322)$. A negative link (even if with lower score) may be observed with some other indexes, such as the Islam Law Conformity Index $(\mathrm{r}=-.158)$, Islamic Traditionalism Index $(\mathrm{r}=-.148)$. On the contrary, the Fundamentalism Index is positively correlated with the Islam Law Conformity Index $(\mathrm{r}=.461)$, the Islamic Traditionalism Index $(\mathrm{r}=.216)$ and negatively correlated with the Islam Openness Index $(\mathrm{r}=-.308)$ (Table 7.21).

Finally, we may underline that the highest ideological consensus is in favor of the Islamic Traditional Index (73\%), on the one hand, and of the Secular

13 All the correlations are statistically significant at .ool. 
TABLE 7.21 Correlation coefficients between indexes

\begin{tabular}{|c|c|c|c|c|}
\hline & $\begin{array}{l}\text { Islamic Law } \\
\text { Conformity } \\
\text { Index }\end{array}$ & $\begin{array}{l}\text { Islamic Tradi- } \\
\text { tionalism Index }\end{array}$ & $\begin{array}{l}\text { Islam } \\
\text { Openness } \\
\text { Index }\end{array}$ & $\begin{array}{c}\text { Secular } \\
\text { Politics Index }\end{array}$ \\
\hline $\begin{array}{l}\text { Islamic Tradition- } \\
\text { alism Index }\end{array}$ & $.448^{* *}$ & & & \\
\hline $\begin{array}{l}\text { Islam Openness } \\
\text { Index }\end{array}$ & $-.304^{* *}$ & $-.190^{* *}$ & & \\
\hline $\begin{array}{l}\text { Secular Politics } \\
\text { Index }\end{array}$ & $-.15^{* * *}$ & $-.148 * *$ & $.364^{* *}$ & \\
\hline $\begin{array}{l}\text { Fundamentalism } \\
\text { Index }\end{array}$ & $.461^{* *}$ & $.216 * *$ & $-.308^{* *}$ & $-.322^{* *}$ \\
\hline
\end{tabular}

SOURCE: AUTHOR'S ELABORATION ON ARAB BAROMETER DATA

TABLE 7.22 Frequencies of indexes grouped in three levels

\begin{tabular}{lccccc}
\hline & $\begin{array}{c}\text { Islam Law } \\
\text { Conformity } \\
\text { Index }\end{array}$ & $\begin{array}{c}\text { Islamic } \\
\text { Traditionalism } \\
\text { Index }\end{array}$ & $\begin{array}{c}\text { Islam } \\
\text { Openness } \\
\text { Index }\end{array}$ & $\begin{array}{c}\text { Secular Politics } \\
\text { Index }\end{array}$ & $\begin{array}{c}\text { Fundamen- } \\
\text { talism Index }\end{array}$ \\
\hline Low & $26 \%$ & $8 \%$ & $28 \%$ & $17 \%$ & $56 \%$ \\
Middle & $34 \%$ & $19 \%$ & $35 \%$ & $30 \%$ & $18 \%$ \\
High & $39 \%$ & $73 \%$ & $38 \%$ & $53 \%$ & $26 \%$ \\
Total & $100 \%$ & $100 \%$ & $100 \%$ & $100 \%$ & $100 \%$ \\
\hline
\end{tabular}

SOURCE: AUTHOR'S ELABORATION ON ARAB BAROMETER DATA

Politics Index (53\%), on the other, followed by the Islam Law Conformity Index $(39 \%)$ and the Islam Openness Index (38\%). Fortunately, the Fundamentalism Index -which may be considered as a radical expression of traditionalism obtains the last position (26\%) (Table 7.22 ).

The positive position gained by secular perspective in the field of politics may be considered as a promising step for the improvement of the democratic dialectics inside Muslim Arab society, even if the past attempts to build secular politics (in Egypt, Iraq, and Syria) have flown into autocratic regimes. 
The presence of religious minorities in hegemonic contests meets, in general, a lot of difficulties, not only for legal reasons (that formally could establish fair rules) but, principally, for social reasons, i.e. for the sense of superiority that majority groups express and apply toward "the others", easily considered deviant and dangerous for the establishment. According to the most positive hypothesis, majority groups may be "tolerant" but rarely "inclusive", i.e. open to mutual relationship.

Lebanon's troubled experiences -marked by bloody conflicts in the 7os and the 8os- are the reasons behind the fact that Lebanese are less optimistic about the effective status of the relationship among Christian minorities and Islamic majorities in their country. On the contrary, it is not unexpected that the most optimistic about this topic are Egyptians, Palestinian and Iraqis (in their countries, in fact, Christian minorities are nearly invisible). There is, in practice, a negative correlation among the effective relevance of Christian minorities in each country and the idyllic representation of their acceptance from Muslim majorities (Table 7.23).

In the perspective of our research, it is, in any case, interesting to analyze the sentiment of social distance towards people concerned with a different religion (mainly Christians) or belonging to different Islamic tradition, such as Shia or Sunni (Jihan, 2017).

In the first hypothesis, $27 \%$ of interviewed does not like to have people of different religion as neighbors, and $18 \%$ like it (the remaining $55 \%$ are indifferent). The refusal overcomes the acceptance in Palestine (28\% vs 19\%) and in Jordan $(21 \%$ vs $10 \%)$, while the contrary happens in Egypt ( $47 \%$ like it $v s 14 \%)$ and in Lebanon ( $29 \%$ vs $14 \%$ ) (Figure 7.1 ).

In the second hypothesis, hostility grows up to $39 \%$, while acceptance decreases to $14 \%$ (with $45 \%$ indifferent) (Figure 7.2). Strong difficulties arise, therefore, inside the Muslim people whose religious and political conflicts affect dramatically the people living outside the Islamic denominations. The hostility is stronger in Egypt ( $50 \%$ vs $14 \%)$ and in Jordan ( $41 \%$ vs $7 \%)$, while tolerance is more widespread in Lebanon ( $31 \%$ vs $15 \%)$, confirming the attitudes and the trends emerged also in the Third Arab Barometer survey.

\section{$7 \quad$ Conclusions}

Every reflection on the ideal relation that should exist between religious belonging and the promotion of a renewed social coexistence -built on the 
TABLE 7.23 How do you view the relationship between Christians (in Egypt: Copts) and Muslims in reality?

\begin{tabular}{|c|c|c|c|c|c|}
\hline & Egypt & Iraq & Lebanon & Palestine & Total \\
\hline $\begin{array}{l}\text { A relationship of } \\
\text { brotherhood, citizen- } \\
\text { ship and cooperation }\end{array}$ & $80 \%$ & $73 \%$ & $39 \%$ & $77 \%$ & $67 \%$ \\
\hline $\begin{array}{l}\text { A relationship strained } \\
\text { as a result of the } \\
\text { cumulative mistakes of } \\
\text { both officials and the } \\
\text { people on both sides }\end{array}$ & $12 \%$ & $6 \%$ & $30 \%$ & $9 \%$ & $14 \%$ \\
\hline $\begin{array}{l}\text { A relationship strained } \\
\text { because of the mistakes } \\
\text { of officials }\end{array}$ & $3 \%$ & $7 \%$ & $16 \%$ & $5 \%$ & $8 \%$ \\
\hline $\begin{array}{l}\text { A relationship strained } \\
\text { because of foreign } \\
\text { conspiracy }\end{array}$ & $5 \%$ & $11 \%$ & $13 \%$ & $5 \%$ & $9 \%$ \\
\hline Do not know & $1 \%$ & $3 \%$ & $1 \%$ & $4 \%$ & $2 \%$ \\
\hline Refuse & - & - & $1 \%$ & - & - \\
\hline Total & $100 \%$ & $100 \%$ & $100 \%$ & $100 \%$ & $100 \%$ \\
\hline
\end{tabular}

SOURCE: AUTHOR'S ELABORATION ON ARAB BAROMETER DATA

respect of the different identities and on the promotion of their right of expression at individual and collective level- must be based on the epochal meeting between Pope Francis and the Grand Imam of Al-Azhar Ahamad alTayyib, which took place in February 2019 in Abu Dhabi, ended with the Document on "Human Fraternity for world peace and living together".14

The first apostolic visit of a Pope in the Arabic peninsula, and the long and intense dialogue with the Islamic religious authorities that made it possible, established a very fruitful opportunity to explain to all religious believers and goodwill people the joining value of faith in God and its reconciling consequences on human and interpersonal relationships. The idea of this Document was itself conceived from a fraternal and open discussion to invite "all persons

14 Document on "Human Fraternity for World Peace and Living Together" signed by His Holiness Pope Francis and the Grand Imam of Al-Azhar Ahamad al-Tayyib (Abu Dhabi, 4 February 2019). 


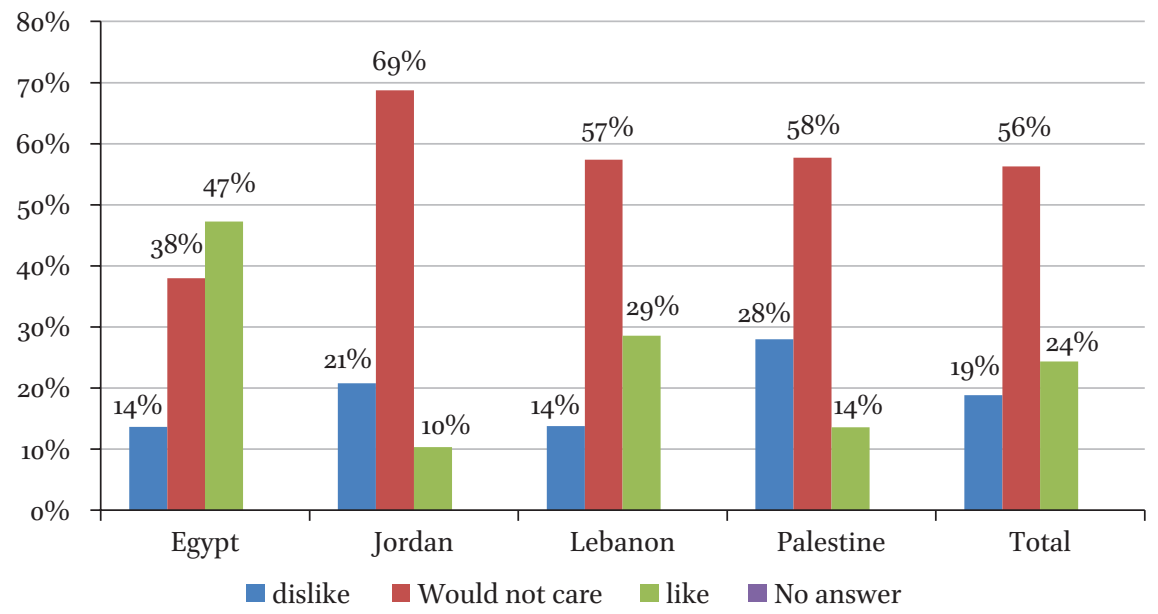

FIGURE 7.1 To have people of a different religion as neighbors SOURCE: AUTHOR'S ELABORATION ON ARAB BAROMETER DATA

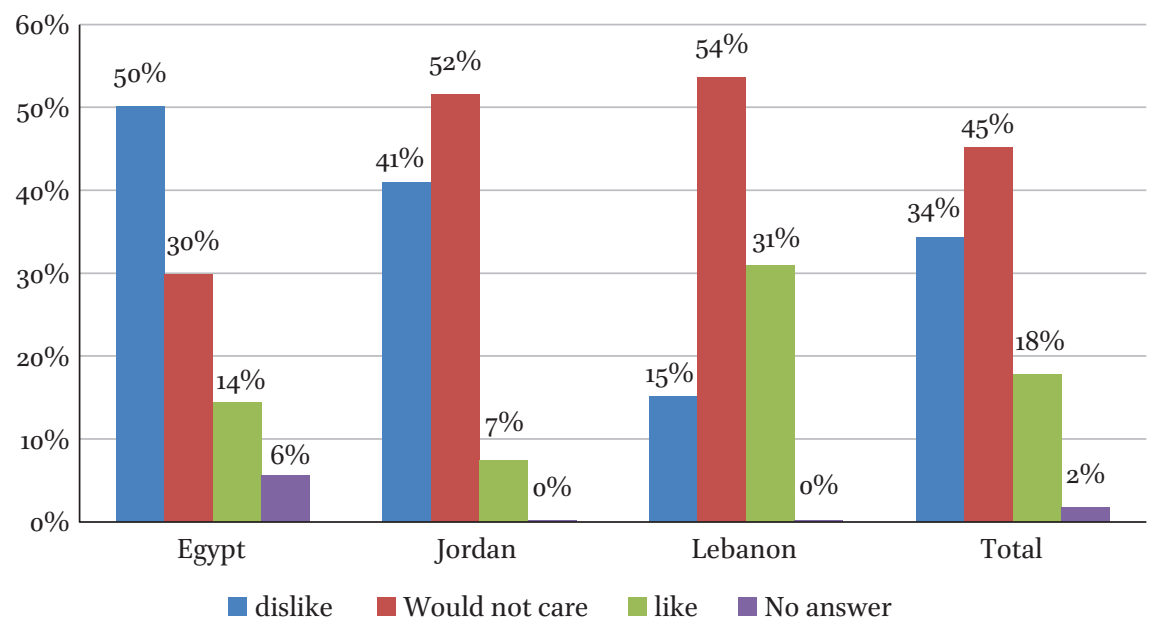

FIGURE 7.2 To have people of a different sect of Islam as neighbors SOURCE: AUTHOR'S ELABORATION ON ARAB BAROMETER DATA

who have faith in God and faith in human fraternity" to work together for promoting the "culture of mutual respect, tolerance, coexistence and peace".

In the foreword of the Document, everybody can read that "Faith leads a believer to see in the other a brother or sister to be supported and loved. Through faith in God, who has created the universe, creatures and all human beings (...) believers are called to express this human fraternity by safeguarding 
creation and the entire universe and supporting all persons, especially the poorest and those most in need".

The Document resolutely declares that "religions must never incite war, hateful attitudes, hostility and extremism, nor must they incite violence or the shedding of blood. These tragic realities are the consequence of a deviation from religious teachings. They result from a political manipulation of religions and from interpretations made by religious groups who, in the course of history, have taken advantage of the power of religious sentiment in the hearts of men and women in order to make them act in a way that has nothing to do with the truth of religion".

The Pope and the Imam invite all the believers "to stop using religions to incite hatred, violence, extremism and blind fanaticism and to refrain from using the name of God to justify acts of murder, exile, terrorism and oppression". In this way, they emphasize the importance of the role of religions in the construction of world peace.

Among the most demanding sentences of the Document -which aim to imprint a turn to the religious and social relations between Muslims and Eastern and Western Christians- we found the solemn obligation to adopt "a culture of dialogue as the path; mutual cooperation as the code of conduct; reciprocal understanding as the method and standard".

The Document is fully aware of the difficulties that prevent the fulfilment of a "bright future for all human beings (the arms race, social injustice, corruption, inequality, moral decline, terrorism, discrimination, extremism and many other causes)". However, it intentionally bets on the deepest desires of every man and woman.

The aim of the Document is very clear, as much as the urgencies and hopes that support it, but it is evident that many efforts should be made to solve the religious, cultural and social conflicts that affect Middle East countries, as we have verified also through the Arab Barometer surveys.

According our empirical data, most of the people interviewed in 2014 and 2016 support the fundamental values at the basis of a pluralistic, tolerant, and democratic political system (freedom of belief, right to practice freely own religion, equal political rights for the religious minorities, same rights of women to education and employment). However, in every country (mainly in Jordan and Palestine), there are significant minorities (well organized and powerful) that do not support a more open society, i.e. a different way to build the coexistence of different identities. In this perspective, also the generational change looks ambivalent: in Jordan and Palestine, many young people are still attracted by Islamic traditionalism more than by its modernization, even if in Egypt and Iraq opposite trends can be observed. Also in Lebanon, that is the most 
pluralistic and tolerant country, the (low) Islamic traditionalism is more attractive for young people.

On the whole, people open to introduce positive changes in civil and political society represent a consistent minority (about 35\%), but they have to face a very conservative and reacting people (about $25 \%$ ) who, in fact, support different kinds of fundamentalism.

From a historical and political point of view, it is evident that in many countries it is impossible to promote and reach a positive coexistence and peace without a true and affordable cooperation among religious leaders and a faithful belonging to the Christian and Islamic religion. Many ancient and contemporary events document the big importance of this kind of relationships, especially in the Middle East region where Christianity and Islam arose and where, nowadays, Christians are a small minority with many social troubles, and Muslims are the largest majority, unfortunately divided by strong and large conflicts between Sunni and Shia.

According to our empirical analysis, we may say that the transition to a more tolerant, civil, and religious coexistence met the largest difficulties among Muslim people, from whom is expected a decisive contribution to peace and prosperity - two fundamental conditions also for the right to not emigrate (Teti, Abbott, 2017). 